\title{
Application of GNSS Methods for Monitoring Offshore Platform Deformation
}

\author{
Khin Cho Myint ${ }^{1, *}$, Abd Nasir Matori ${ }^{1}$, and Adel Gohari ${ }^{1}$ \\ ${ }^{1}$ Department of Civil and Environmental Engineering, Universiti Teknologi PETRONAS, 32610 \\ Tronoh, Malaysia
}

\begin{abstract}
Global Navigation Satellite System (GNSS) has become a powerful tool for high-precision deformation monitoring application. Monitoring of deformation and subsidence of offshore platform due to factors such as shallow gas phenomena. GNSS is the technical interoperability and compatibility between various satellite navigation systems such as modernized GPS, Galileo, reconstructed GLONASS to be used by civilian users. It has been known that excessive deformation affects platform structurally, causing loss of production and affects the efficiency of the machinery on board the platform. GNSS have been proven to be one of the most precise positioning methods where by users can get accuracy to the nearest centimeter of a given position from carrier phase measurement processing of GPS signals. This research is aimed at using GNSS technique, which is one of the most standard methods to monitor the deformation of offshore platforms. Therefore, station modeling, which accounts for the spatial correlated errors, and hence speeds up the ambiguity resolution process is employed. It was found that GNSS combines the high accuracy of the results monitoring the offshore platforms deformation with the possibility of survey.
\end{abstract}

\section{Introduction}

Offshore structures are usually deployed several kilometres into the sea and at a given depth [1]. In the last several decades, deformation of offshore platforms was observed to be due to the presence of shallow gas reservoir compaction phenomena. It can cause the structural subsidence and deformation, which will affect the integrity of these structures. In addition, such excessive subsidence may result in the loss of human lives as well as infrastructure [2].

Offshore structural subsidence is monitored regularly in order to anticipate and prevent the consequences there in. However, due to their physical locations, accurate measurement of such subsidence becomes a challenge [3]. Conventional GNSS measurement is a method that can be used to obtained centimetre-level accuracy measurement by effectively taking away biases and errors caused by atmospheric interference [4]. The use of reference station networks has become the global solution for high precision satellite positioning applications. Therefore, this research aims to determine the deformation magnitude and

\footnotetext{
* Corresponding author: khinchomyint07@gmail.com
} 
direction of the monitored offshore platforms using high precision GNSS coordinates for the three (3) stations on the platform.

\subsection{Global Navigation Satellite Systems (GNSS)}

Within the last three decades, GNSS techniques have been used in land survey for photo control and geodetic control networks. The use of GNSS usually relies on some precise carrier-phase measurements where ambiguities were successfully fixed [5]. The advancements in modern technology have further enhanced the use of such technology in which 24-hour usage with a full complement of satellites is possible. Currently, GNSS technology are developed for mapping and surveying tasks such as real-time deformation monitoring, setting out survey as well as camera positioning aerial photography. Therefore, ambiguity resolution (AR), which comprises of ambiguity estimation and evaluation has become the key for precision in GNSS applications [5].

In GNSS applications, the successful resolutions and integer uncertainties are both important and challenging undertakings most especially in terms of GPS positioning [6][7]. At present, the major topic of concern for high precision GNSS application is the carrier phase ambiguity resolution [8]. Due to memory and speed constraints, the efficiency of the calculation is of major importance as time taken for the ambiguities to be resolved in to consideration [9] [10]. Under different navigational environments, accurate and dependable positions solutions involve a number of procedures [11] [12] namely; message decoding, inter ambiguity resolution, GNSS positioning, navigation and augmentation data availability monitoring, data correction and position calculation [13].

\subsection{Offshore deformation}

Offshore structural deformation such as subsidence poses a serious and potentially dangerous consequences. It is reported in [14] that the process of hydrocarbon extraction may cause reservoir compaction which in turn, could result in severe structural subsidence. For example, reservoir compaction was reported to have caused a subsidence of up to $50 \mathrm{~cm}$ by Bedrige oil field in which a revenue loss of up to USD200 million was recorded [15]. Offshore structures are normally located several kilometers offshore, one of the famous techniques for their monitoring is the use of GPS $[16,17]$. The method proves to be a means for monitoring of system deformations where both human safety as well as cost saving is achieved.The object of this study is to observe the deformation of offshore platforms using Global Navigational Satellite System (GNSS).

\section{Methodology}

\subsection{Study Area}

The study area selected as West Lutong offshore platform, which is approximately $20 \mathrm{~km}$ from Miri coastline in Sarawak. Offshore platforms are subject to deform in horizontal and vertical directions over time, and these are due to instability of the platform and other factors such as plate motion or post-seismic motion of an earthquake. Platform deformation monitoring is one of the routine which implementing by Oil and Gas Company to detect and estimate the motion rate and the displacement magnitude between epochs. 


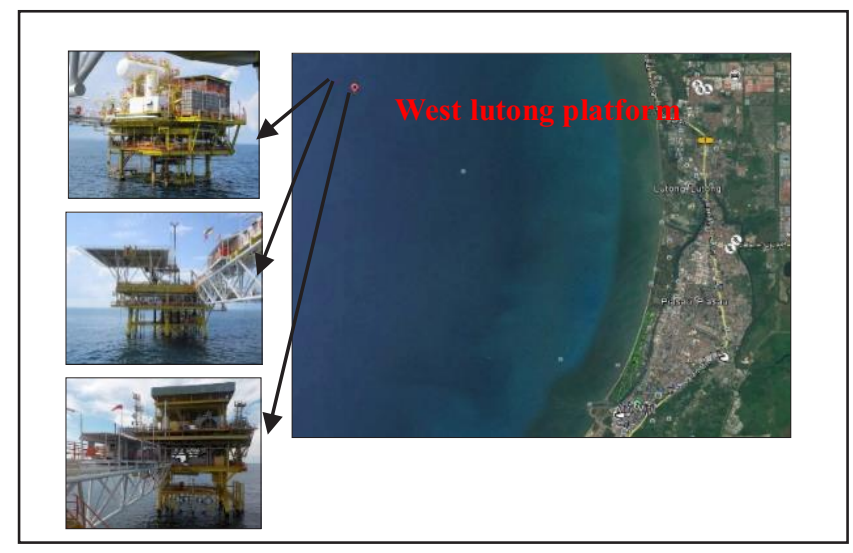

Fig.1. West Lutong platform is located $20 \mathrm{~km}$ from Miri coastline in Sarawak.

\subsection{Materials and Method}

The material includes GNSS receivers, and GNSS data processing using Bernese and Matlab programming software. The method has been divided into two parts in this study. Firstly, it includes experimental work; conducting field measurement trials to study as well as collect GNSS data- considering different navigation settings and measurement scenarios. Secondly, methodology which towards the developing long baseline based on GNSS result on offshore platforms.

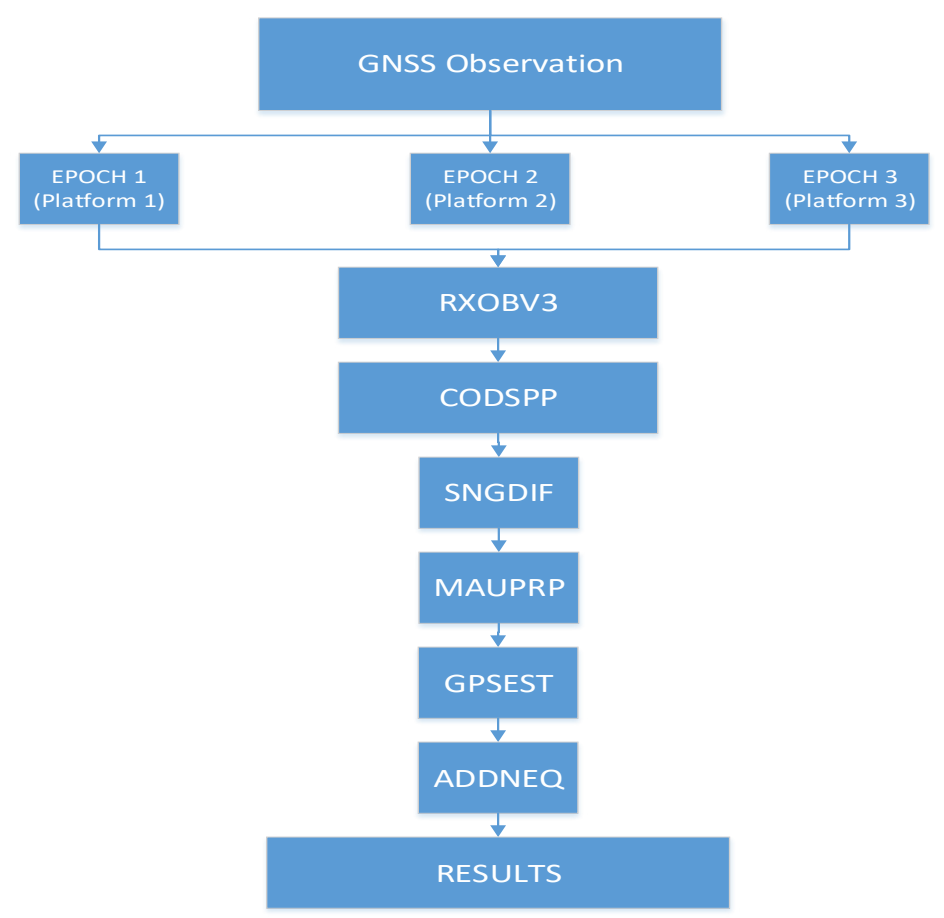

Fig. 2. The processing of the BERNESE Software. 


\section{Results and discussions}

GNSS data was observed from 2013 and 2014 in West Lutong platform. The survey of observation was conducted 24 hours and 15 intervals second. During the time of observation, the data were received the position and type of satellite in GNSS receiver. Data processing and adjustment were carried out using appropriate scientific Bernese processing software. The Secondary Layer of the processing especially on stations repeatability analyses as well as for the final coordinate adjustment. The result of Platform deformation monitoring is to detect and estimate the motion rate and the displacement magnitude between epochs. It investigates the existing processing strategies to identify the preferred processing approach that can support precise positioning for offshore platform deformation monitoring. The results of Ellipsoid Height for each platform are shown in Table 1 .

Table 1. Ellipsoid Height (M) of West Lutong Platforms.

\begin{tabular}{|c|c|c|c|}
\hline Station & Parameter & $\mathbf{2 0 1 3}$ & $\mathbf{2 0 1 4}$ \\
\hline WL01 & Ellipsoid Height (M) & 62.520 & 62.523 \\
\hline WL02 & Ellipsoid Height (M) & 64.302 & 64.320 \\
\hline WL03 & Ellipsoid Height (M) & 49.635 & 49.663 \\
\hline
\end{tabular}

Table 2. Data of GNSS result for West Lutong Platforms.

\begin{tabular}{|c|c|c|}
\hline Station & $\mathbf{2 0 1 3}$ & $\mathbf{2 0 1 4}$ \\
\hline WL01 & 0.0 & -0.003 \\
\hline WL02 & 0.0 & -0.018 \\
\hline WL03 & 0.0 & -0.028 \\
\hline
\end{tabular}

The offshore platforms are located in marine environment; the GPS signals will be subjected to more influence of multipath due to sea surface reflection of the signals. Based on the GNSS observation data Figure 3 shows the plot of the relative deformation of all the three platforms between 2013 and 2014 as obtained. It can be seen from the result that the deformation up to $0.028 \mathrm{~m}$ was recorded for platform 3 while deformation of platform 1 was deform less than $0.005 \mathrm{~m}$. Platform 2 movement was shown between $0.005 \mathrm{~m}$ and $0.02 \mathrm{~m}$ during the observation. Although vertical movements can be occurred for the platforms due to uplift force from wave and win action, it may also be due to GNSS measurement errors such as satellite multipath errors, orbit errors, ionospheric error and tropospheric errors. 


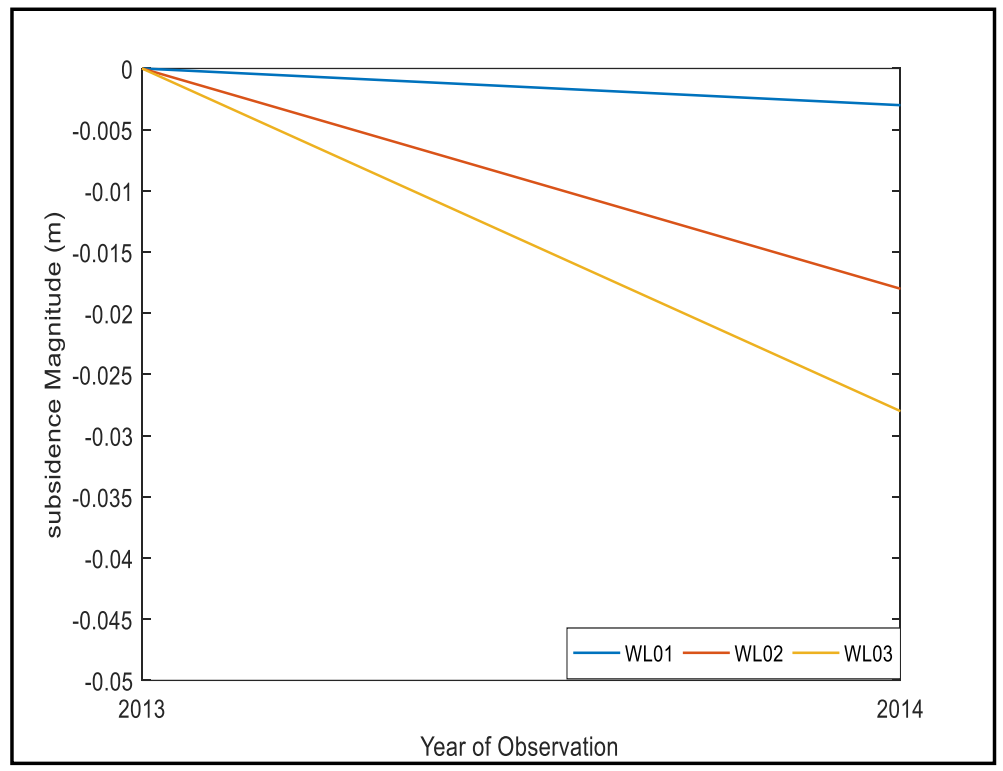

Fig. 3. Deformation observed for West Lutong Platform 2013 and 2014.

\section{Conclusions}

GNSS observations are widely used for monitoring deformation applications, geodesy, agriculture, Transportation and others surveying. Continuously Operating References Stations (CORS) are being installed in federal, state and private infrastructue in order to obtain the precise position. However, consequent upon the fact that most of the offshore platform in Malaysia waters are loactaed up to $200 \mathrm{~km}$ offshore. The application of GPS in offshore monitoring is become very limtted. Therefore, there is strong need for the development of GNSS method for monitoring of offshore platform in deeper waters. In addition, elimination of systematic error such as multipath and atmospheric effectt as wel as satellite orbic error become difficult in the processing of the algorithms of baseline GNSS data. Consequently, these errors becomes problem in high precision applications as the results of their effect in ambiguity resolution process. Hence it becomes important to propose a better algorithm for data processing in which a good precision can be obtained in offshore deformation studies.

\section{References}

1. J., Peuchen, Geotechnical and geophysical site characterization 4, 83-112 (2012).

2. A., Badellas, P., Savvaidis, Papageorgiou Publ. Co, 257 (1990).

3. H., Euler, C., Keenan, B., Zebhauser, G., Wübbena, ION GPS, 11-14 (2001)

4. J., Aponte, X., Meng, C., Hill, T., Moore, M., Burbidge, A., Dodson, Journal of Applied Geodesy 3, 25-34 (2009).

5. $\quad$ N. Widjajanti, Universiti Teknologi Petronas (2010).

6. J. Haasdyk, C. Roberts, and V. Janssen, FIG Congress, Sydney, Australia, 11-16 (2010)

7. C. Rizos, S. Han, Wuhan University Journal of Natural Sciences 8, 566-574 (2003). 
8. P. Loomis, L. Sheynblatt, and T. Mueller, Proceedings of the 4th International Technical Meeting of the Satellite Division of the Institute of Navigation (ION GPS 1991), 511-520 (1991)

9. R. B. Langley, GPS world 8, 40-45 (1997).

10. T. Yan, Positioning 1, (2005).

11. L. Wanninger, Proceedings of the 8th International Technical Meeting of the Satellite Division of the Institute of Navigation, ION GPS-95, 55-62 (1995)

12. C. J. Deckert, P. V. Bolstad, Southern Journal of Applied Forestry 20, 81-84 (1996).

13. D. N. Dong, Y. Bock, Journal of Geophysical Research: Solid Earth 94, 3949-3966 (1989).

14. E. J. Fielding, R. G. Blom, R. M. Goldstein, Geophysical Research Letters 25, 32153218 (1998).

15. A. Sroka, R. Hejmanowski, Proceedinds $12^{\text {th }}$ FIG Symposium, Baden (2006).

16. H. Setan, R. Othman, Positioning 1 (2006).

17. A.N. Matori, H. Setan, J. Platform 1(2000). 